\title{
The Second to Fourth Digit Ratio and Age at First Marriage in Semi-Nomadic People from Namibia
}

\author{
Piotr Sorokowski • Agnieszka Sorokowska • \\ Dariusz Danel · Mara L. Mberira · Leszek Pokrywka
}

Received: 23 June 2010 / Revised: 7 March 2011 / Accepted: 3 July 2011 / Published online: 1 November 2011

(C) The Author(s) 2011. This article is published with open access at Springerlink.com

\begin{abstract}
The second to fourth digit ratio (2D:4D) is used as a potential marker for prenatal androgen exposure. It is associated with many behavioral and biological variables, including fertility and sexual behavior. However, direct association between 2D:4D and reproductive success-in populations where no contraceptives are used - has not been investigated. Here, we present a study conducted among the semi-nomad Himba population living in northern Namibia. 2D:4D ratios were calculated for a sample of this population ( $N=99 ; 60$ women, 39 men), and the results were correlated with age, marital status, age at first marriage, number of children, and number of marriages. As found in the majority of previous studies, males had lower 2D:4D ratios than females. The 2D:4D ratio did not correlate with number of children. Females and males with a more masculine 2D:4D were married earlier and were more likely to have a husband or wife. We suggest that mating preferences for females with masculine 2D:4D are related to masculinity of phenotypic and personality traits of such women, which are beneficial in harsh environmental conditions and/or higher facial masculinity, which influences the perceived age of an individual. At the same time, masculine (physically strong,
\end{abstract}

\section{P. Sorokowski $(\square) \cdot$ A. Sorokowska}

Institute of Psychology, University of Wroclaw, ul. Dawida 1, 50-527 Wroclaw, Poland

e-mail: sorokowskipiotr@yahoo.co.uk

\section{Danel}

Institute of Anthropology, Polish Academy of Science,

Wroclaw, Poland

M. L. Mberira

Faculty of Humanities and Social Science, University of Namibia,

Windhoek, Namibia

L. Pokrywka

Ragna Jentofts 3b, 7900 Rørvik, Norway dominant, and hardworking) males might gather resources necessary to marry their first wife earlier.

Keywords 2D:4D - Sex hormones - Age at first marriage · Reproductive success $\cdot$ Sex differences $\cdot$ Himba (Namibia)

\section{Introduction}

Exposure to different levels of sex hormones in utero leaves effects on human fingers. People exposed to elevated levels of testosterone tend to have ring fingers (the fourth digit: 4D) longer than their index fingers (the second digit: 2D). Estrogen exposure has the opposite effect; the index finger tends to be longer than the ring finger. Therefore, the ratio between the length of second and fourth manual digits (2D:4D) is a sexually dimorphic trait-males tend to have lower 2D:4D values that females (Ecker, 1875; George, 1930, Manning, Scutt, Wilson, \& Lewis-Jones, 1998) and it seems to be a cross-cultural trait (Manning, Henzi, Venkatramana, Martin, \& Singh, 2003; Manning, Stewart, Bundred, \& Trivers, 2004; Manning et al., 2000). Males develop a lower 2D:4D than females by the end of the first trimester of gestation (Galis, Ten Broek, Van Dongen, \& Wijnaendts, 2010; Malas, Dogan, Evcil, \& Desdicioglu, 2006). Because of the early fetal development of sexual dimorphism in 2D:4D, it is suggested that 2D:4D may serve as a biomarker for prenatal androgen exposure (Gallup, Frederick, \& Pipitone, 2008; Lutchmaya, Baron-Cohen, Raggatt, Knickmeyer, \& Manning, 2004; Manning et al., 1998).

Over the past few years, this hypothesis has generated much interdisciplinary research interest (for review, see Gallup et al., 2008; Voracek \& Loibl, 2009). 2D:4D was shown to be a correlate of a multitude of sex-dependent, hormonally influenced variables such as behavioral, cognitive, personality, and somatic traits, adultonset disorders, and measures related to fertility and sexuality (for review, see Manning, 2002). For example, many studies showed 
that low 2D:4D ratios correlated with athletic ability (Manning, Morris, \& Caswell, 2007; Manning \& Taylor, 2001) and male aggression (Bailey \& Hurd, 2005; McIntyre et al., 2007). On the other hand, results regarding other variables were less homogenous. For example, some studies investigating relations between finger digit ratios and sexual orientation reported that homosexual men have higher 2D:4D than heterosexual men (Manning, Churchill, \& Peters, 2007; McFadden \& Shubel, 2002), some that homosexual men have lower 2D:4D than heterosexual men (Rahman, 2005; Rahman \& Wilson, 2003), and other that there is no significant difference between 2D:4D in homo- and heterosexual men (Voracek, Manning, \& Ponocny, 2005; Williams et al., 2000). The latest meta-analysis regarding 2D:4D and sexual orientation (Grimbos, Dawood, Burriss, Zucker, \& Puts, 2010) showed that there was no difference between heterosexual and gay men (but heterosexual women had more feminine 2D:4D than did lesbians). Additionally, ethnicity explained some between-studies variation in men. This example shows that different results regarding 2D:4D might be obtained and further comparative studies regarding this issue are necessary.

Another poorly investigated issue concerns cross-racial differences in sexual dimorphism of 2D:4D. Surprisingly, 2D:4D varies across nations and these cross-national differences are noticeably larger than the sex differences found within nations (Manning, Churchill, et al., 2007; Manning et al., 2000, 2003, 2004). As Voracek and Dressler (2006) discussed, these differences are poorly understood and, therefore, cross-cultural studies concerning 2D:4D are still interesting. Until 2006, samples from more than 25 different countries or ethnic groups were collected and investigated, but the participants were mainly White (Voracek \& Dressler, 2006). Data regarding indigenous populations are still lacking (see Table 1).

One of the most interesting questions is whether 2D:4D correlates with the reproductive success (RS) of an individual. The most important study investigating the relation of 2D:4D and RS was conducted by Manning and Fink (2008). They analyzed results from 153,429 participants from the BBC Internet Study and found significant negative associations between 2D:4D and number of children for males, and positive correlations between 2D:4D and number of children for females (right and left 2D: 4D). Other correlates of reproductive success were also investigated (preferred age at first child, frequency of sex, strength of sex drive, and how easily participants were sexually excited, etc.). In general, males showed negative and females positive associations between 2D:4D and correlates of reproductive success. These results were consistent with previous outcomes. Manning et al. (2000) found that couples for whom there was a large difference between the female's 2D:4D ratio and the male's 2D:4D ratio (very feminine woman and very masculine man) had the highest fertility and these differences were independent of age (Manning et al., 2000). However, it is worth noting that none of the above-mentioned studies presented any lear hypothesis why 2D:4D should correlate with an individual's reproductive success. As Hönekopp, Bartholdt, Beier, and Liebert (2007) showed that 2D:4D was not related to levels of circulating sex hormones in adults, the obtained differences in reproductive success (Manning \& Fink, 2008; Manning et al., 2000) might be an effect of differences in human sexual behavior rather than levels of circulating sex hormones.

Such suggestions might be confirmed by other studies. For example, Hönekopp, Voracek, and Manning (2006) showed that right hand 2D:4D (but not left hand 2D:4D) was significantly negatively associated with reported number of lifetime sexual partners per individual. However, this issue requires further investigation since the results of other studies are not that consistent. Putz, Gaulin, Sporter, and McBurney (2004), Rahman, Korhonen, and Aslam (2005), and van Dongen (2009) did not detect associations between digit ratios and number of sexual partners.

Table 1 Digit ratio (2D:4D) in selected populations from Africa and Asia

\begin{tabular}{|c|c|c|c|c|c|c|c|}
\hline \multirow[t]{2}{*}{ Population (study) } & \multicolumn{3}{|c|}{ Males } & \multicolumn{3}{|c|}{ Females } & \multirow[t]{2}{*}{ Cohen's $d$} \\
\hline & $n$ & $2 \mathrm{D}: 4 \mathrm{D}$ & $S D$ & $n$ & 2D:4D & $S D$ & \\
\hline Andoni (Obolo): Nigeria (Gwunireama, Osunwoke, \& Orish, 2010) & 350 & .95 & .03 & 352 & .96 & .05 & $.24 * * *$ \\
\hline Yourba: Nigeria (Oladipo, Fawehinimi, Edibamode, Osunwoke, \& Ordu, 2009) & 210 & .96 & .04 & 210 & .97 & .04 & $.25^{*}$ \\
\hline Sugali \& Yanadi: India (Manning et al., 2003) & 80 & .96 & .04 & 80 & .97 & .04 & $.25^{*}$ \\
\hline Uygur (children): China (Manning et al., 2004) & 209 & .94 & .04 & 229 & .95 & .03 & $.27 * *$ \\
\hline Igbo: Nigeria (Oladipo et al., 2009) & 210 & .96 & .04 & 210 & .97 & .03 & $.28 *$ \\
\hline Zulu: South Africa (Manning et al., 2003) & 66 & .94 & .03 & 72 & .95 & .03 & .34 \\
\hline Berbers (children): Morocco (Manning et al., 2004) & 54 & .95 & .04 & 36 & .96 & .03 & .37 \\
\hline $\begin{array}{l}\text { Almadinah Almonawarah (indirect method): Saudi Arabia } \\
\text { (Almasry, El Domiaty, Algaidi, Elbastawisy, \& Safwat, 2011) }\end{array}$ & 276 & .96 & .03 & 284 & .98 & .04 & $.48 * * *$ \\
\hline Han (children): China (Manning et al., 2004) & 59 & .94 & .03 & 59 & .96 & .03 & $.67 *$ \\
\hline Himba: Namibia (this study) & 39 & .94 & .06 & 58 & 1.00 & .08 & $.84 * * *$ \\
\hline Manipal (children): India (Kanchan \& Pradeep Kumar, 2010) & 175 & .95 & .03 & 175 & .99 & .03 & $1.34 * * *$ \\
\hline
\end{tabular}

$* p<.05 ; * * p<.01 ; * * * p<.001$ 
It is also important that the studies investigating the relation between 2D:4D and reproductive success were conducted only among White people (even in the study of Manning and Fink (2008) non-White participants were excluded from the analyses). Therefore, it is possible that further results would be influenced by possible racial differences. For example, in the aforementioned studies of Manning, Churchill, et al. (2007), the relationship between sexual orientation and 2D:4D was most apparent in White people with no evidence for such a pattern in Black and Chinese people. What is more, in Western populations, usage of contraceptives or even preferred number of children might have a moderating effect on reproductive success (and studies investigating the relation of $2 \mathrm{D}: 4 \mathrm{D}$ ratio and usage of contraceptives have not been conducted so far). Thus, the use of 2D:4D as predictor of particular life history traits appears to require further study, particularly in non-White populations of low civilization development and natural birth control. Therefore, the purpose of this study was to evaluate sex differences in 2D:4D and the relationship between 2D:4D and direct or indirect measures of RS in a semi-nomad, African population.

\section{Method}

\section{Participants}

The study was conducted among the Himba (Ovahimba) tribe of northern Namibia (Kunene region). The Himba are a culturally isolated ethnic group — one of a few ethnic groups in modern Africa who have preserved their traditional lifestyle, including wearing traditional clothing, as well as maintaining all the beliefs and customs of their ancestors. They are semi-nomadic, pastoral people. Himba men herd cattle and goats and sometimes hunt. Women perform most other tasks, including milking cows, fetching water from wells, and caring for children. Kunene is a region of harsh desert climate and Himba are exposed to climatic challenges (drought), health risks from lifestyle activities, malnutrition, and pathogen stress (Bollig, 2005; Malan, 2004). Because of their conservatism and cultural rules, they rarely mate with other tribes and form a homogenous population (Malan, 2004). They are a polygamic society. Generally, men marry at the late stage in their life. Usually the first marriage is arranged, often with a very young girl (Bollig, 2005).

Reliable statistics regarding the Himba people are hard to be found. The last three censuses in Kunene region did not include the ethnic affiliation of people (Bollig, 2005). Therefore, demographic statistics below describe the whole Kunene region (The Namibia 2001 Population and Housing Census) inhabited by Himba, but also by Ovambo, Nama, and Herero people. Among women above 15 years, $52 \%$ were never married, $41 \%$ were married (however, only $12 \%$ with certificate), $2 \%$ were divorced or separated, and $4 \%$ were widowed. On average, women had 4.7 children. Life expectancy at birth for women was 57 and for men
50 years. Because of cultural and environmental reasons, the data might differ between particular ethnic groups. The data from studies regarding only Himba are generally outdated and were usually collected in samples of not more than 100 people. One of the recent studies (Bollig, 2005) showed that men had approximately 1.5 wives and the fertility rate for women was 3.2 child (which is very similar to the results of our study).

Our participants inhabited Opuwo (18.06S, 13.84E) and several small, surrounding villages in the Kunene region (northwest region of Namibia, about $750 \mathrm{~km}$ from the capital of Namibia-Windhoek). We used a convenience sampling method. All adults present in the villages at the time of the visit were invited to participate in the study. Percentage of refusals was extremely small. Ninety-nine subjects participated in the study (60 women, 39 men). Generally, it is more difficult to locate Himba men than women, for they usually pasture, hunt or work outside of the villages. None of the participants used contraceptives. Three participants who had visible deformation of one of fingers were excluded from the analyses regarding this finger.

The study was a part of a larger project conducted among the Himba people. For their participation in this study, the subjects were paid about 3 USD.

\section{Procedure}

The participants were interviewed by one of the authors (M.M.) who knew their local dialect. They were asked questions regarding their marital and reproductive history - marital status, total number of wives at present and in the history (question for men only), age at first marriage, total number of children and grandchildren, and the number still alive (and their age at death). The age of each participant was self-estimated. Although Himba people have a specific understanding of time, it is a longitudinal concept for them (chronology is based upon important episodes and occasional conditions of the region in which they live; Gibson, 1977). The question about age in "Western years" was absolutely understandable. However, some participants did not know exactly how old they were (when they were born) and were giving an approximate age.

In order to measure 2D:4D and other finger lengths, a photograph of participants' hands was taken. Because of technical reasons, we decided to take pictures of one hand only-right, since sexual dimorphism in 2D:4D is higher in it (Manning, Churchill, et al., 2007; Manning \& Fink, 2008; Putz et al., 2004) and changes in hand morphology with age are stronger in the left hand (Trivers, Manning, \& Jacobson, 2006). We used a Nikon D80 camera with a 18-200 Nikkor lens. Participants stretched their hand with splayed fingers across a transparent glass surface, which was provided to assure the standard hand position. A photograph was taken from a distance of approximately $50 \mathrm{~cm}$. The finger lengths were calculated manually from the photographs using the computer program Paint.net v3.36. The measurements were performed by the authors of the study (PS, AS, 
and DD). The measurers were blind to the subjects' interview results. Relative Technical Error of Measurement (rTEM) was calculated (Kemper \& Schwerdtfeger, 2009; Ulijaszek \& Kerr, 1999) - aggregated rTEM for three raters equaled $1.35 \%$, which is considered an acceptable amount of error (rTEM $<1.5 \%$ ), even for skilled anthropometrists (Norton \& Olds, 1996).

Data analyses included calculation of descriptive statistics, comparing means with $t$-tests, Spearman rank correlations, multiple regression models with categorical variable and analysis of covariance with contrast analysis. Since the numbers of participants varied in particular analyses, appropriate degrees of freedom were adjusted accordingly. All analyses were performed with Statistica 9.1.

\section{Results}

Descriptive statistics (means and $S D$ ) of the sample were as follows: for males, $N=39$, age: $50.1 \pm 18.4$ years, children: $6.2 \pm 7.1$, age at first marriage: $28.0 \pm 8.7$, number of wives: $1.6 \pm 1.1$ (33\% of men had more than one wife at the time of the study). For females, $N=58$, age: $38.9 \pm 18.4$ years, children: $3.1 \pm 2.4$, age at first marriage: $14.9 \pm 9.8$.

Males had a lower 2D:4D value than females (2D:4D right hand: males $.939 \pm .056$, females .996 $\pm .077, t(95)=4.01$, $p=.0001$, Cohen's $d=.84)$. All the remaining finger ratios are shown in Table 2.
Of the various measures obtained, age at first marriage provided the strongest relationship with the 2D:4D ratio. Multiple regression model with age at first marriage as a dependent variable and 2D:4D and sex (categorical: $0=$ female, $1=$ male) as independent variables was significant, adjusted $r^{2}=.45, F(2$, $76)=32.33, p<.00001$. Both digit ratio $(\beta=.38, t=4.19, p<$ $.0001)$ and $\operatorname{sex}(\beta=.73, t=7.95, p<.00001)$ were related to the age at first marriage. Women entered marriage earlier than men and lower digit ratio lowered the age of first marriage in both sexes (Fig. 1).

None of the other measures presumed to be related to RS proved to be strongly related to the $2 \mathrm{D}: 4 \mathrm{D}$ ratio. A multiple regression model was employed in analysis of possible

Table 2 Sexual dimorphism in digit ratio in Himba (Namibia) sample

\begin{tabular}{|c|c|c|c|c|c|c|c|c|}
\hline \multirow{2}{*}{$\begin{array}{l}\text { Digit } \\
\text { ratio }\end{array}$} & \multicolumn{3}{|c|}{ Females } & \multicolumn{3}{|c|}{ Males } & \multirow{2}{*}{$\begin{array}{l}\text { Difference } \\
(p \text { value })\end{array}$} & \multirow{2}{*}{$\begin{array}{l}\text { Cohen's } \\
d\end{array}$} \\
\hline & $n$ & $M$ & $S D$ & $n$ & $M$ & $S D$ & & \\
\hline $2 \mathrm{D}: 3 \mathrm{D}$ & 58 & .918 & .056 & 39 & .870 & .041 & $\begin{array}{c}t(95)=4.61 \\
p<.0001\end{array}$ & .96 \\
\hline 2D:4D & 58 & .996 & .077 & 39 & .938 & .055 & $\begin{array}{c}t(95)=4.01 \\
p<.001\end{array}$ & .84 \\
\hline 2D:5D & 57 & 1.260 & .111 & 38 & 1.190 & .122 & $\begin{array}{c}t(93)=4.01 \\
p<.001\end{array}$ & .62 \\
\hline 3D:4D & 58 & 1.085 & .062 & 39 & 1.078 & .035 & $t(95)<1$ & .14 \\
\hline 3D:5D & 57 & 1.371 & .099 & 38 & 1.366 & .112 & $t(93)<1$ & .06 \\
\hline 4D:5D & 58 & 1.264 & .072 & 38 & 1.267 & .082 & $t(93)<1$ & .03 \\
\hline
\end{tabular}

Fig. 1 Digit ratio and age at first marriage in Himba (Namibia) sample

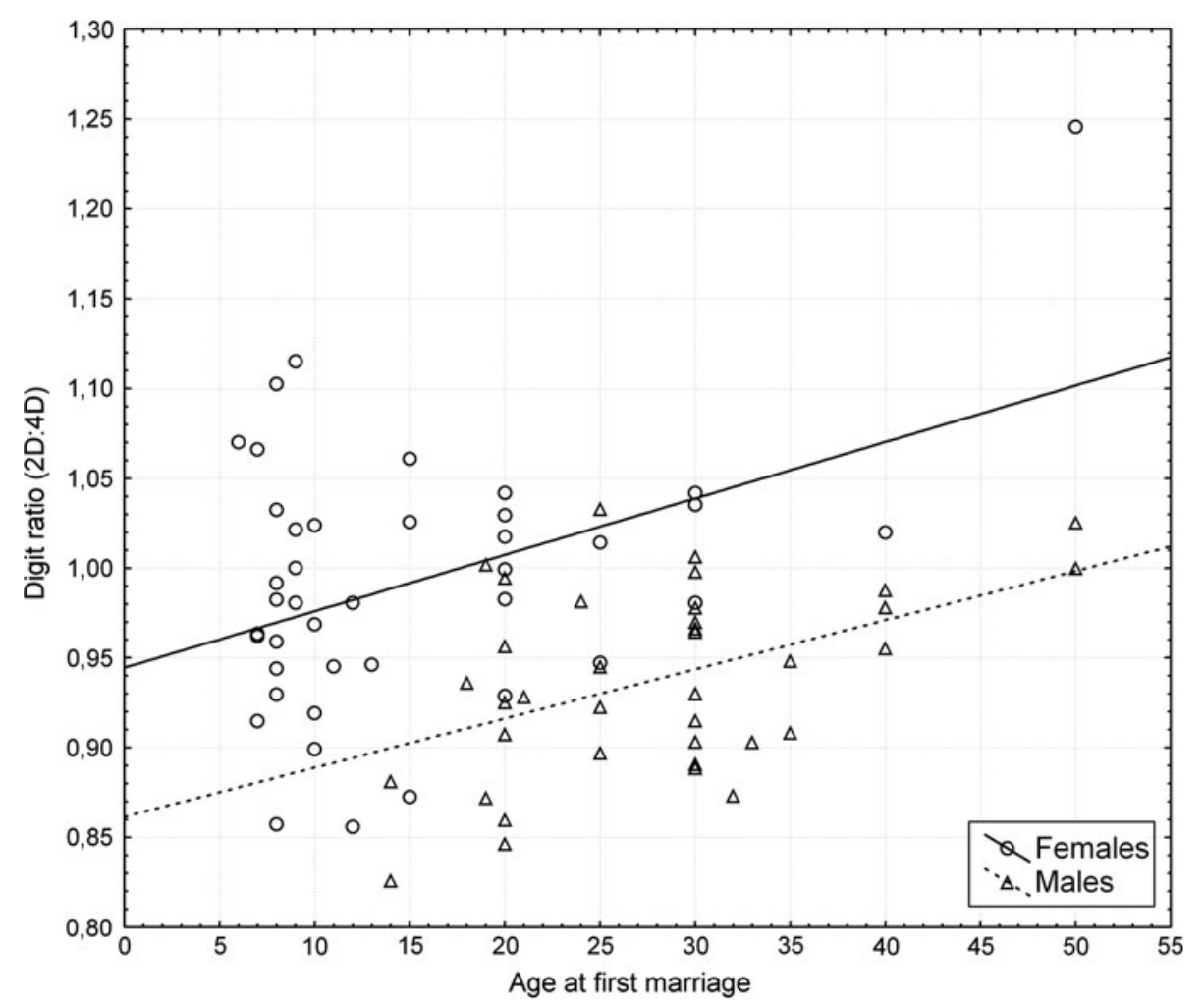


relationship between number of children (dependent variable) and three predictors: digit ratio, age, and sex. In order to meet the assumptions of the current regression model, number of children was transformed by finding the logarithm of number of children. Then, number of children was increased by one, allowing to include into log-transformation childless individuals. The overall model was statistically significant, $F(3,93)=11.8, p<$ .00001 , and accounted for $25.24 \%$ (adjusted $r^{2}$ ) of transformednumber-of-children variance. However, among three analyzed dependent variables, only participants' age was related to the log-transformed-number-of-children $(\beta=.46, t=4.98, p<$ $.00001)$. As could have been predicted, older participants had more children. The effects of $2 \mathrm{D}: 4 \mathrm{D}(\beta=.11, t=1.13)$ and sex $(\beta=.15, t=1.54)$ were statistically non-significant.

Similar results were obtained for number of children (logtransformed) who reached 14 years of age. There were no individuals who lost all their children, therefore, simple log-transformation were used. Although the whole model appeared to be statistically significant, $F(3,81)=6.72, p<.001$, again, only participants' age was positively associated with number of children who reached the age of fourteen. Other predictors were statistically non-significant (2D:4D: $\beta=.10, t<1$; sex: $\beta=.20$, $t=1.74)$.

To investigate whether 2D:4D differs among ever married and never married females (males were excluded due to low a number of unmarried individuals), analysis of covariance (ANCOVA) was used. Design of this study included two categories of marriage status (ever married/never married) and women's age as covariate. The effect of marriage was marginally significant, $F(1,55)=3.91, p=.05$, partial $\eta^{2}=.07$. The "ever married" females had lower digit ratio comparing to "never married" ones $(.99 \pm .012$ vs. $1.02 \pm .018$, respectively). The effect of the covariate, women's age, was statistically non-significant, $F(1,55)=$ 1.52 .

\section{Discussion}

Our study confirmed the existence of sexual dimorphism of 2D:4D values found in previous studies. Males had lower 2D:4D values than females. We found significant differences in 2D:4D between females and males in the Himba population, which shows that this trait is sexually dimorphic irrespective of race and origin. Both in comparison with previous studies conducted among White populations (for review, see Hönekopp \& Watson, 2010) and non-Western/indigenous populations, the observed sexual difference in 2D:4D and its effect size were relatively large (see Table 1). This might be a consequence of the interlocus coevolution of sexually antagonistic genes process, which may promote in utero androgenization of the male fetus in polygynous populations like Himba (Manning et al., 2000; see also other possible explanations in their article). Although the investigated sample was not large, the results suggest that the effect of the difference in digit ratio between males and females in Black populations can be at least as strong as in White populations.

There exist only a few studies regarding all digit ratios and none of them were conducted in a non-White population (McFadden \& Shubel, 2002; McIntyre, Cohn, \& Ellison, 2006; Voracek \& Offenmüller, 2007); therefore, it is hard to generate hypotheses on their basis. This is why we did not analyze additionally our results. However, such data might be useful in further research and the database of our raw data for our sample is available upon request for research purposes.

We did not find any relationship between 2D:4D and reproductive success. This result is surprising in the context of previous studies conducted in White populations (Manning et al., 2000; Manning \& Fink, 2008). However, it is commonly known that fertility remains under control of circulating sex hormones in humans (for review, see Burrows, 2003). Therefore, no relationship between 2D:4D and reproductive success in a population of natural birth control seems to confirm that 2D:4D is not related to levels of circulating sex hormones in adults (Hönekopp et al., 2007). However, this is a first study conducted among such a specific population and it is likely that in different native populations other results would be obtained. Further research is necessary to draw any convincing conclusions.

It is very interesting that $2 \mathrm{D}: 4 \mathrm{D}$ values were related to the age at first marriage in Himba population. We found that the unmarried women had more feminine 2D:4D than "ever" married women. We do not know exactly who "never married" women were. However, they were not widows (because widows were included as "ever married" women in the analysis), neither were they very young (non-significant difference between age of "never married"; $M=33.94$ and "ever married" women $M=$ 41.12). What is more, females and males with masculine 2D:4D values married earlier.

In males, this result might be easily explained. Males with more masculine 2D:4D have higher physical fitness (Manning, Churchill, et al., 2007; Manning \& Taylor, 2001), are more aggressive and dominant (Bailey \& Hurd, 2005; Manning \& Fink, 2008; McIntyre et al., 2007) and have a higher tendency to take risks (Apicella et al., 2008), what in natural environmental conditions might be important in gathering food and other goods, and acquiring higher social status (for discussion on how hunting influences social status, see Smith, 2004). It seems likely that masculine (physically strong, dominant, and hardworking) men gather resources necessary to marry their first wife earlier. However, we did not collect data regarding wealth; therefore, direct confirmation of such hypothesis is impossible.

The relationship between age at first marriage and 2D:4D in women seems much more interesting. Two possible explanations of the obtained result might be suggested. First, women with traits that correlate with masculine 2D:4D might be more attractive as mates in Himba. Physical attractiveness, physical 
fitness, and personality traits adaptive to difficult life conditions, correlating with masculine 2D:4D, might be important factors in mate preferences in Himba. Second, masculine 2D:4D might be related to higher facial masculinity, which influences the perceived age of an individual.

Physical attractiveness is associated with 2D:4D. It has been found that 2D:4D was related to self-reported ratings of attractiveness in men and women (Manning \& Quinton, 2007). Additionally, masculinization of 2D:4D correlated with high (masculine) waist-to-hip ratio (WHR) (Fink, Neave, \& Manning, 2003) and, in some culturally isolated populations, men tend to prefer higher WHR than men in Western countries (Furnham \& Baguma, 1994; Yu \& Shepard, 1998). What is more, female facial symmetry has been found to be negatively correlated with 2D:4D (Fink, Manning, Neave, \& Grammer, 2004) and facial symmetry is considered to be one of the most important features of attractiveness (Thornhill \& Gangestad, 1993). Bilateral symmetry of the face appears to be even more strongly preferred by isolated hunter-gatherer populations (Hadza) than in the UK (Little, Apicella, \& Marlowe, 2007).

Physical fitness of a female mate is probably more important in traditional populations than in Western populations because women perform more hard work there. The level of physical activity required for pre-agricultural lifestyles is, on average, much greater than that for Western females. The ability of a female to work hard physically seems to be more important to Hadza males than to U.S. college students (Marlowe, 2004). 2D:4D is negatively related to physical fitness in both young males and females (Hönekopp, Manning, \& Müller, 2006). For example, 2D:4D explains about $25 \%$ of the variance in endurance running in males and females, and more masculine 2D:4D is connected with better endurance (Manning, Morris, et al., 2007). Therefore, the preference for Himba females with more masculine 2D:4D could be explained by preference for women of better physical condition, which is important for life within a traditional population.

What is more, more masculine 2D:4D correlates with more masculine behavior in women and men. Hampson, Ellis, and Tenk (2008) found that lower 2D:4D ratios were associated with increased aggressiveness and sensation-seeking in both males and females. Also, dominance negatively correlated with 2D:4D (Manning \& Fink, 2008). Similarly, as in the case of men, masculinity of women's personality traits seems to fit well in populations that experience hard life conditions, such as the Himba.

Summing up, physically strong, fit, able to work hard, and resistant females are possibly the best partners when it is necessary to struggle for survival. Masculine 2D:4D ratio can be a marker of those characteristics. That is why Himba women with low 2D:4D could marry earlier. This hypothesis is in agreement with other result obtained in Himba population - contrary to Western societies (Fink, Neave, Brewer, \& Pawlowski, 2007; Pawlowski, 2003), 31\% of Himba men preferred partners of height that was equal to their own, and $21 \%$ that was even higher than their own (Sorokowski, Sorokowska, Fink, \& Mberira, 2011). Men in Western countries choose female partners shorter than themselves possibly because they do not face the ecological constraints that are present in indigenous societies. This study might be another indirect proof of preferences for higher masculinity in female mates in highly demanding environments.

Other possible explanation of the relationship between 2D: $4 \mathrm{D}$ and age at fist marriage exists. Some evidence suggests that masculine 2D:4D can be linked with facial masculinity (Fink et al., 2005; Neave, Laing, Fink, \& Manning, 2003; but see Koehler, Simmons, \& Rhodes, 2004) and feminine 2D:4D is associated with feminine facial characteristics in women (but not in men; Burris, Little, \& Nelson, 2007). It has also been shown that higher facial masculinity increases perceived age of an individual (Boothroyd et al., 2005). In the traditional populations, marriage usually takes place when an individual reaches biological maturity, and as Himba only approximate the actual age of an individual, assessment of people's age might be influenced by their looks. Therefore, if lower 2D:4D-higher masculinity - is related to higher perceived age, the more masculine boys and girls might be perceived as more sexually and emotionally mature. It is likely that such individuals get married relatively earlier. This hypothesis, however, seems to explain better the results regarding women than men-mean age at first marriage for women was 14.9 and for men 28.0, which shows that men are generally mature when they get married.

Although our study is one of the first to investigate relationships between 2D:4D and some sexual behaviors in an indigenous population, it has some limitations. First, the sample size was relatively small and number of participants and mean age were different for male and female groups. Second, 2D:4D was measured only for the right hand. What is more, the explanations provided in this article are "post factum" and are only interpretations of the obtained results, not a description of an actual mating mechanism. It would be interesting to conduct simple, direct research in which Himba would be interviewed about their mating preferences. The fact that some marriages in this population are arranged (without love) is not an obstaclemature men probably choose certain partners for some reasons. Another issue that might extend the research area would be data regarding indirect fitness (sibling's children). Therefore, it would be interesting to replicate our study in some other traditional tribes where anthropological studies are being conducted (Hadza, Tsimane, etc.).

In conclusion, sexual dimorphism in the 2D:4D (lower in males, higher in females) is a culturally independent trait. We found that females and males with masculine 2D:4D were characterized by lower age at first marriage. This result suggests that high prenatal testosterone (low 2D:4D) might influence mate attractiveness in this culturally isolated population or/and increase the perceived age of the individuals. 
Acknowledgments We would like to thank the Editor and the anonymous reviewers for their help. This work was supported by Foundation for Polish Science (scholarship START) and University of Wrocław (grant 2900/W/IPS/08) to the first author.

Open Access This article is distributed under the terms of the Creative Commons Attribution Noncommercial License which permits any noncommercial use, distribution, and reproduction in any medium, provided the original author(s) and source are credited.

\section{References}

Almasry, S. M., El Domiaty, M. A., Algaidi, S. A., Elbastawisy, Y. M., \& Safwat, M. D. (2011). Index to ring digit ratio in Saudi Arabia at Almadinah Almonawarah province: A direct and indirect measurement study. Journal of Anatomy, 218, 202-208.

Apicella, C. L., Dreber, A., Campbell, B., Gray, P. B., Hoffman, M., \& Little, A. C. (2008). Testosterone and financial risk preferences. Evolution and Human Behavior, 29, 384-390.

Bailey, A. A., \& Hurd, P. L. (2005). Finger length ratio (2D:4D) correlates with physical aggression in men but not in women. Biological Psychology, 68, 215-222.

Bollig, M. (2005). Risk management in a hazardous environment: A comparative study of two pastoral societies. New York: Springer.

Boothroyd, L. G., Jones, B. C., Burt, D. M., Cornwell, R. E., Little, A. C., Tiddeman, B. P., et al. (2005). Facial masculinity is related to perceived age but not perceived health. Evolution and Human Behavior, 26, 416-431.

Burris, R. P., Little, A. C., \& Nelson, E. C. (2007). 2D:4D and sexually dimorphic facial characteristics. Archives of Sexual Behavior, 36, 377-384.

Burrows, H. (2003). Biological actions of sex hormones. Cambridge: Cambridge University Press.

Ecker, A. (1875). Einige Bemerkungen über einen schwankenden charakter in der hand des menschen. Archiv für Anthropologie, 8, 67-74.

Fink, B., Grammer, K., Mitteroecker, P., Gunz, P., Schaefer, K., Bookstein, F. L., \& Manning, J. T. (2005). Second to fourth digit ratio and face shape. Proceedings of the Royal Society of London Series $B, 272,1995-2001$.

Fink, B., Manning, J. T., Neave, N., \& Grammer, K. (2004). Second to fourth digit ratio and facial asymmetry. Evolution and Human Behavior, 25, 125-132.

Fink, B., Neave, N., Brewer, G., \& Pawlowski, B. (2007). Variable preferences for sexual dimorphism in stature (SDS): Further evidence for an adjustment in relation to own height. Personality and Individual Differences, 43, 2249-2257.

Fink, B., Neave, N., \& Manning, J. T. (2003). Second to fourth digit ratio, body mass index, waist-to-hip ratio, and waist-to-chest ratio: Their relationships in heterosexual men and women. Annals of Human Biology, 30, 728-738.

Furnham, A., \& Baguma, P. (1994). Cross-cultural differences in the evaluation of male and female body shapes. International Journal of Eating Disorders, 15, 81-89.

Galis, F., Ten Broek, C. M. A., Van Dongen, S., \& Wijnaendts, L. C. D. (2010). Sexual dimorphism in the prenatal digit ratio (2D:4D). Archives of Sexual Behavior, 39, 57-62.

Gallup, G. G., Frederick, M. J., \& Pipitone, R. N. (2008). Morphology and behavior: Phrenology revisited. Review of General Psychology, 12, 297-304.

George, R. (1930). Human finger types. Anatomical Record, 46, 199_ 204.

Gibson, G. D. (1977). Himba epochs. History in Africa, 4, 67-121.
Grimbos, T., Dawood, K., Burriss, R. P., Zucker, K. J., \& Puts, D. A. (2010). Sexual orientation and the second to fourth finger length ratio: A meta-analysis in men and women. Behavioral Neuroscience, 124, 278-287.

Gwunireama, I. U., Osunwoke, E. A., \& Orish, C. N. (2010). Anthropometrical study of the second and fourth digit ratio of Andoni (Obolo) groups of Ijaw ethnic nationality in Nigeria. Journal of Applied Biosciences, 27, 1732-1735.

Hampson, E., Ellis, C. L., \& Tenk, C. M. (2008). On the relation between 2D:4D and sex-dimorphic personality traits. Archives of Sexual Behavior, 37, 133-144.

Hönekopp, J., Bartholdt, L., Beier, L., \& Liebert, A. (2007). Second to fourth digit length ratio (2D:4D) and adult sex hormone levels: New data and a meta-analytic review. Psychoneuroendocrinology, 32, 313-321.

Hönekopp, J., Manning, J. T., \& Müller, C. (2006). Digit ratio (2D:4D) and physical fitness in males and females: Evidence for effects of prenatal androgens on sexually selected traits. Hormones and Behavior, 49, 545-549.

Hönekopp, J., Voracek, M., \& Manning, J. T. (2006). 2nd to 4th digit ratio (2D:4D) and number of sex partners: Evidence for effects of prenatal testosterone in men. Psychoneuroendocrinology, 31, 3037.

Hönekopp, J., \& Watson, S. (2010). Meta-analysis of digit ratio 2D:4D shows greater sex difference in the right hand. American Journal of Human Biology, 22, 619-630.

Kanchan, T., \& Pradeep Kumar, G. (2010). Index and ring finger ratioA morphologic sex determinant in South-Indian children. Forensic Science, Medicine, and Pathology, 6, 255-260.

Kemper, C. J., \& Schwerdtfeger, A. (2009). Comparing indirect methods of digit ratio (2D:4D) measurement. American Journal of Human Biology, 21, 188-191.

Koehler, N., Simmons, L. W., \& Rhodes, G. (2004). How well does second-to-fourth-digit ratio in hands correlate with other indications of masculinity in males? Proceedings of the Royal Society of London, Series B, 271, 296-298.

Little, A. C., Apicella, C. L., \& Marlowe, F. W. (2007). Preferences for symmetry in human faces in two cultures: Data from the UK and the Hadza, an isolated group of hunter-gatherers. Proceedings of the Royal Society B, 274, 3113-3117.

Lutchmaya, S., Baron-Cohen, S., Raggatt, P., Knickmeyer, R., \& Manning, J. T. (2004). 2nd to 4th digit ratios, fetal testosterone and estradiol. Early Human Development, 77, 23-28.

Malan, J. S. (2004). Peoples of Namibia. Windhoek: Rhino Publishers.

Malas, M. A., Dogan, S., Evcil, E. H., \& Desdicioglu, K. (2006). Fetal development of the hand, digits and digit ratio (2D:4D). Early Human Development, 82, 469-475.

Manning, J. T. (2002). Digit ratio: A pointer to fertility, behavior, and health. New Brunswick, NJ: Rutgers University Press.

Manning, J. T., Barley, L., Walton, J., Lewis-Jones, D. I., Trivers, R. L., Singh, D., ... Szwed, A. (2000). The 2nd:4th digit ratio, sexual dimorphism, population differences, and reproductive success: Evidence for sexually antagonistic genes? Evolution and Human Behavior, 21, 163-183.

Manning, J. T., Churchill, A. J. G., \& Peters, M. (2007). The effects of sex, ethnicity and sexual orientation on self-measured digit ratio (2D:4D). Archives of Sexual Behavior, 36, 223-233.

Manning, J. T., \& Fink, B. (2008). Digit ratio (2D:4D), dominance, reproductive success, asymmetry, and sociosexuality in the BBC Internet Study. American Journal of Human Biology, 20, 451-461.

Manning, J. T., Henzi, P., Venkatramana, P., Martin, S., \& Singh, D. (2003). Second to fourth digit ratio: Ethnic differences and family size in English, Indian, and South African populations. Annals of Human Biology, 30, 579-588.

Manning, J. T., Morris, L., \& Caswell, N. (2007). Endurance running and digit ratio (2D:4D): Implications for fetal testosterone effects 
on running speed and vascular health. American Journal of Human Biology, 19, 416-421.

Manning, J. T., \& Quinton, S. (2007). Association of digit ratio (2D:4D) with self-reported attractiveness in men and women: Evidence from the BBC internet survey. Journal of Individual Differences, $28,73-77$.

Manning, J. T., Scutt, D., Wilson, J., \& Lewis-Jones, D. I. (1998). The ratio of 2nd to 4th digit length: A predictor of sperm numbers and concentrations of testosterone, luteinizing hormone and oestrogen. Human Reproduction, 13, 3000-3004.

Manning, J. T., Stewart, A., Bundred, P. E., \& Trivers, R. L. (2004). Sex and ethnic differences in 2nd to 4th digit ratio of children. Early Human Development, 80, 161-168.

Manning, J. T., \& Taylor, R. P. (2001). Second to fourth digit ratio and male ability in sport: Implications for sexual selection in humans. Evolution and Human Behavior, 22, 61-69.

Marlowe, F. W. (2004). Mate preferences among Hadza hunter-gatherers. Human Nature, 15, 365-376.

McFadden, D., \& Shubel, E. (2002). Relative lengths of fingers and toes in human males and females. Hormones and Behavior, 42, 492 500 .

McIntyre, M. H., Barrett, E. S., McDermott, R., Johnson, D. D. P., Cowden, J., \& Rosen, S. P. (2007). Finger length ratio (2D:4D) and sex differences in aggression during a simulated war game. Personality and Individual Differences, 42, 755-764.

McIntyre, M. H., Cohn, B. A., \& Ellison, P. T. (2006). Sex dimorphism in the digital formulae of children. American Journal of Physical Anthropology, 129, 143-150.

Namibian National Planning Commission. (2001). Population and Housing Census. Retrieved from http://www.npc.gov.na/census/index. $\mathrm{htm}$.

Neave, N., Laing, S., Fink, B., \& Manning, J. T. (2003). Second to fourth digit ratio, testosterone and perceived male dominance. Proceedings of the Royal Society of London B, 270, 2167-2172.

Norton, K., \& Olds, T. (1996). Anthropometrica: A textbook of body measurement for sports and health courses. Sydney: UNSW Press.

Oladipo, G. S., Fawehinimi, H. F., Edibamode, E. I., Osunwoke, E. A., \& Ordu, K. S. (2009). Second to forth digit ratio in Nigerian Igbos and Yourbas. Scientific Research and Essay, 4, 1146-1148.

Pawlowski, B. (2003). Variable preferences for sexual dimorphism in height as a strategy for increasing the pool of potential partners in humans. Proceedings of the Royal Society of London, B, 270, 709712.

Putz, D. A., Gaulin, S. J. C., Sporter, R. J., \& McBurney, D. H. (2004). Sex hormones and finger length: What does 2D:4D indicate? Evolution and Human Behavior, 25, 182-199.
Rahman, Q. (2005). Fluctuating asymmetry, second to fourth finger length ratios and human sexual orientation. Psychoneuroendocrinology, 30, 382-391.

Rahman, Q., Korhonen, M., \& Aslam, A. (2005). Sexually dimorphic 2D:4D ratio, height, weight, and their relation to number of sexual partners. Personality and Individual Differences, 39, 83-92.

Rahman, Q., \& Wilson, G. D. (2003). Sexual orientation and the 2nd to 4th finger length ratio: Evidence for organizing effects of sex hormones or developmental instability? Psychoneuroendocrinology, $28,288-303$.

Smith, E. A. (2004). Why do good hunters have higher reproductive success? Human Nature, 15, 343-364.

Sorokowski, P., Sorokowska, A., Fink, B., \& Mberira, M. (2011). Variable preferences for sexual dimorphism in stature (SDS) might not be universal: Data from a semi nomad population (Himba) in Namibia. Journal of Cross-Cultural Psychology. doi:10.1177/002 2022110395140.

Thornhill, R., \& Gangestad, S. W. (1993). Human facial beauty: Averageness, symmetry and parasite resistance. Human Nature, 4, 237-269.

Trivers, R., Manning, J. T., \& Jacobson, A. (2006). A longitudinal study of digit ratio (2D:4D) and other finger ratios in Jamaican children. Hormones and Behavior, 49, 150-156.

Ulijaszek, S. J., \& Kerr, D. A. (1999). Anthropometrics measurement error and the assessment of nutritional status. British Journal of Nutrition, 82, 165-177.

van Dongen, S. (2009). Second to fourth digit ratio in relation to age, BMI and life history in a population of young adults: A set of unexpected results. Journal of Negative Results, 6, 1-7.

Voracek, M., \& Dressler, S. G. (2006). High (feminized) digit ratio (2D:4D) in Danish men: A question of measurement method? $\mathrm{Hu}$ man Reproduction, 21, 1329-1331.

Voracek, M., \& Loibl, L. M. (2009). Scientometric analysis and bibliography of digit ratio (2D:4D) research, 1998-2008. Psychological Reports, 104, 922-956.

Voracek, M., Manning, J. T., \& Ponocny, I. (2005). Digit ratio (2D:4D) in homosexual and heterosexual men from Austria. Archives of Sexual Behavior, 34, 335-340.

Voracek, M., \& Offenmüller, D. (2007). Digit ratios (2D:4D and other) and relative thumb length: A test of developmental stability. Perceptual and Motor Skills, 105, 143-152.

Williams, T. J., Pepitone, M. E., Christensen, S. E., Cooke, B. M., Huberman, A. D., Breedlove, N. J., ... Breedlove, S. M. (2000). Finger-length ratios and sexual orientation. Nature, 404, 455-456.

Yu, D. W., \& Shepard, G. H. (1998). Is beauty in the eye of the beholder? Nature, 396, 321-322. 